\title{
An asymptomatic case of pneumatosis cystoids intestinalis: A case report
}

\author{
Alessandra Loiodice ${ }^{1 *}$, Lucia Montenegro ${ }^{1}$, Mariangela Loiacono ${ }^{1}$, Isabella Franco ${ }^{1}$ and Ippazio Ugenti ${ }^{1,2}$ \\ ${ }^{1}$ Department Unit of Digestive Endoscopy, I.R.C.C.S. Istituto Tumori "Giovanni Paolo II", Bari, Italy \\ ${ }^{2}$ D.E.T.O.- University of Bari "Aldo Moro"
}

\begin{abstract}
Introduction: pneumatosis cystoides intestinalis is an uncommon disease characterized by the presence of gas within the submucosa or subserosa of the intestine. Pneumatosis cystoides intestinalis can be often localized in colon and it may be asymptomatic.

Case presentation: A 53's man, with an autistic spectrum disorder and no other comorbidities nor symptoms, underwent a colonoscopy because of finding of a wall thickening of the rectum on the last abdominal computerized tomography. The colonoscopy revealed the presence of multiple cysts, resembling a bunch of grapes at the left-colonic flexure with normal overlying mucosa.
\end{abstract}

Conclusion: pneumatosis cystoides intestinalis may be asymptomatic or sometimes diagnosed incidentally during colonoscopy. The treatment approach depends on underlying cause and it can be conservative or surgical in restricted cases.

\section{Introduction}

Pneumatosis cystoides intestinalis (PCI) is an uncommon disease with an unknown etiology, characterized by the presence of gas within the submucosa or subserosa of the intestine [1]. PCI can be localized anywhere within the gastrointestinal tract [2]. PCI may be asymptomatic or sometimes diagnosed incidentally during colonoscopy requested for various symptoms (i.e., abdominal pain, diarrhoea) [3] and treatment approach is related on the underlying cause.

\section{Case Report}

A 53's-man, outpatient, with an autistic spectrum disorder and no other comorbidities, underwent surgery and radiotherapy on 2012 for a seminoma and was on annual follow up with CT. The last one showed a wall thickening of the rectum. So, he underwent a colonoscopy. In the period of the colonoscopy, he had no abdominal symptoms, laboratory findings were normal, and he was not taking any therapy. The colonoscopy revealed the presence of multiple cysts, resembling a bunch of grapes and compressible with forceps, at the left-colonic flexure. The overlying mucosa was normal, confirmed by use of NBI (Figure 1-3). Furthermore, the rectum and the other colonic segments were normal. A subsequent review of CT images confirmed the presence of gas collections within the left-colonic flexure wall (Figure 4). So, we confirmed the diagnosis of PCI and prescribed rifaximin therapy.

\section{Discussion}

Pneumatosis cystoides intestinalis (PCI) is an uncommon disease with an unknown etiology, characterized by the presence of gas within the submucosa or subserosa of the intestine. In a recent study about Chinese population including $239 \mathrm{PCI}$ cases, was found a M:F ratio of 2,4:1 and the mean age of patients was $45.3 \pm 15.6$ years (range: $2-81$ years) [1]. PCI can be localized anywhere within the gastrointestinal tract from the oesophagus to the rectum: it involves the large intestine

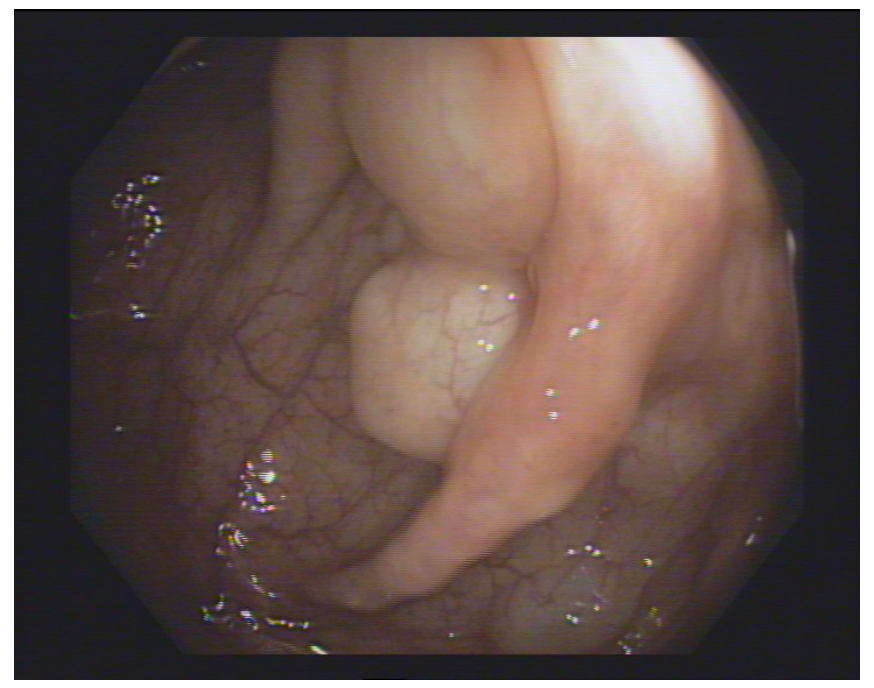

Figure 1. Multiple cysts with overlying normal mucosa, resembling a bunch of grapes at the left-colonic flexure

in $46 \%$ of the cases, the small intestine in $27 \%$ of the cases, the stomach in $5 \%$ of the cases and both large and small intestine in $7 \%$ of the cases [2].

*Correspondence to: Alessandra Loiodice, viale Orazio Flacco 65, 70124 Bari, Italy, Tel: +393497924283; E-mail: a.loiodice@oncologico.bari.it

Key words: pneumatosis cystoides intestinalis, asyntomatic, colonoscopy, case report

Received: March 03, 2021; Accepted: March 11, 2021; Published: March 15, 2021 


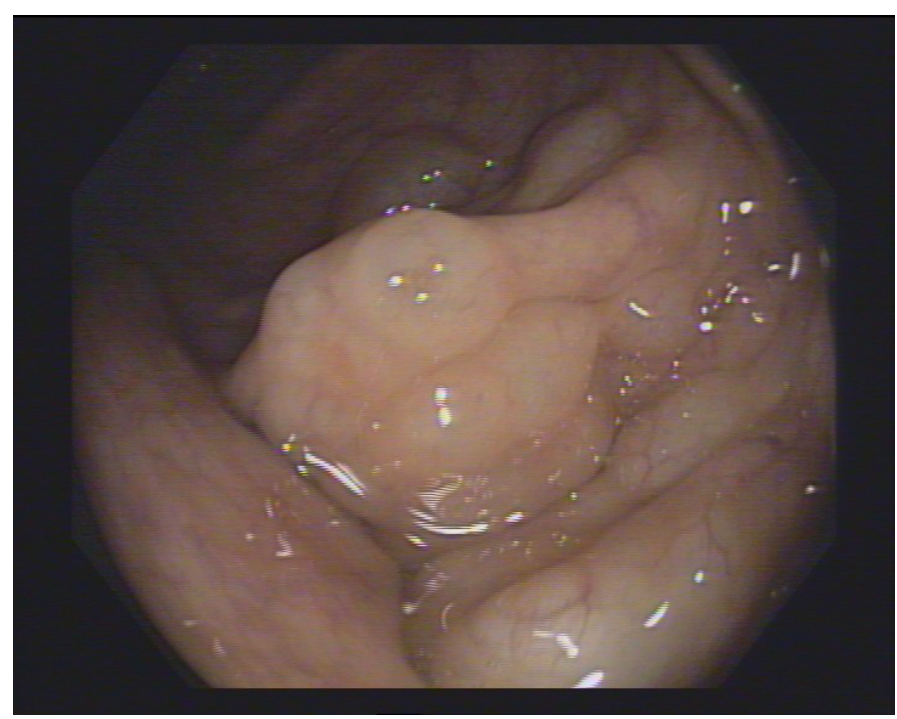

Figure 2. Multiple cysts with overlying normal mucosa, resembling a bunch of grapes at the left-colonic flexure

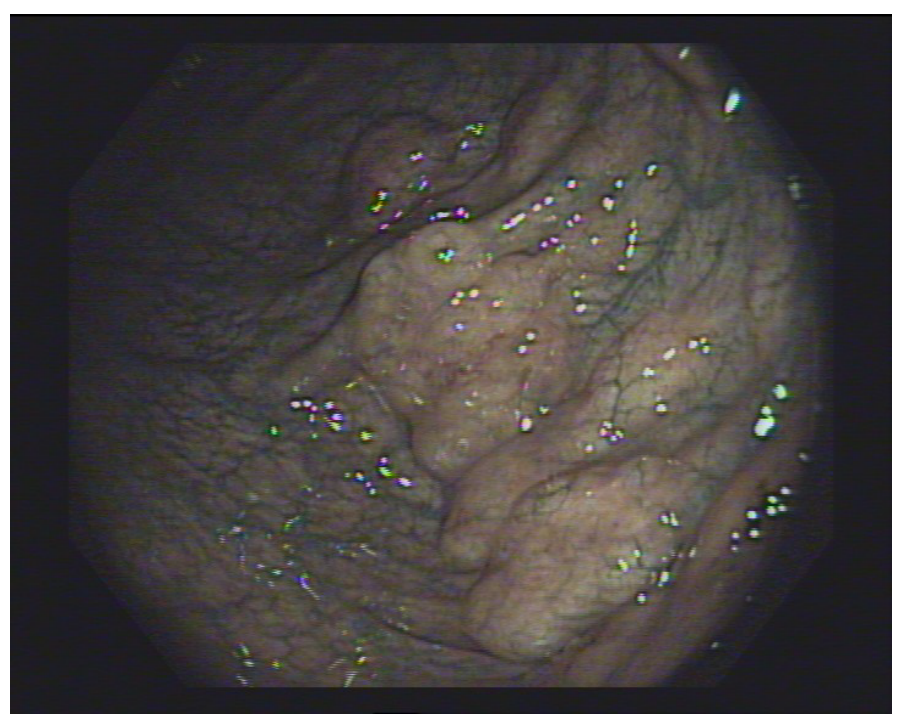

Figure 3. NBI use confirmed normal appearance of mucosa

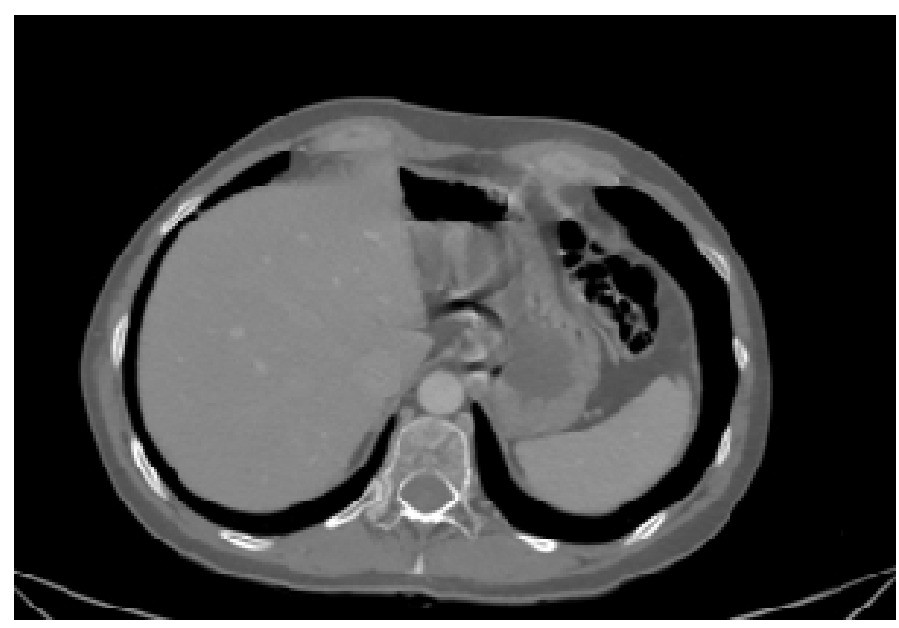

Figure 4. CT-scan image
PCI is mainly asymptomatic and is often diagnosed incidentally, as in our case; some cases present with diarrhoea or constipation, abdominal pain, bloody stool, loss of appetite, weight loss, and even severe events as perforation or pneumoperitoneum $[2,4]$. PCI can be divided into primary (15\%) and secondary (85\%) types [5]. Various gastrointestinal and non-gastrointestinal diseases has been considered as causes of secondary types of PCI, such as bowel ischemia [6], inflammatory bowel diseases, bowel infection, gastroduodenal ulcer, necrotizing enterocolitis [5], pyloric stenosis [7], diverticular disease [5], obstructive pulmonary disease [8], drugs (e.g., alpha-glucosidase inhibitors) $[9,10]$, collagen tissue diseases $[11,12]$, acquired immune deficiency syndrome [13] and malnutrition [4,5,14]. Anywhere none of these symptoms and diseases affected our patient, so his type of PCI can be cosidered as primary type.

\section{Pathogenesis}

Various theories have been proposed to explain the gas passage or formation in the submucosa or subserosal.

1) the mechanical theory: ischemia, obstruction, traumas, surgery, or even biopsies during a colonoscopy, could cause increase of intraluminal pressure, wall injury and allow the passage of gas within intestinal wall. However, this does not explain why gas remains within intestinal wall [1].

2) the bacterial theory: an increased mucosal permeability and the presence of gas-producing bacteria, in particular hydrogen, could cause the gas passage within the wall. A support to this theory is the disappearance of PCI after antimicrobial therapy [15]. Some authors have demonstrated the appearance of PCI in animals with intestinal infection by Clostridium perfringes [16]. However, is not possible isolate or cultivate bacteria from the cysts.

3) the pulmonary theory: pulmonary diseases, such as chronic obstructive pulmonary disease (COPD), asthma, and interstitial pneumonia, may result in pulmonary alveolar rupture and movement of gas through the mediastinum and retroperitoneum and locates within the bowel mesentery. In some cases, alveolar gas dissects along the aorta, through the diaphragm and into the mesenteric blood vessels and then becoming trapped in the bowel wall. A support to this theory is the presence in literature of various case reports of PCI in patients with pulmonary diseases $[17,18,19]$. However, this theory alone doesn't explain the fact that hydrogen, a gas that human cells aren't able to produce, may be represent up to $50 \%$ of the gas content within the cysts. Nevertheless, many patient affected by PCI are not affected by pulmonary diseases [20]. None of these three theories completely explain the pathogenesis of PCI, perhaps it is more likely a combination of two or more theories.

\section{Diagnosis}

Nowadays because of the increase of number of colonoscopies for colorectal cancer screening, it is possible to find PCI incidentally in asymptomatic patients. The endoscopic appearance is the presence of gas-filled blebs resembling a bunch of grapes. The mucosa is often normal or thin or sometimes has erosions or erythema. Sometimes PCI could be mistaken with polyps or submucosal lesions. Typically, blebs collapse when biopsed [21]. In symptomatic patient, for example those with abdominal pain, it's more frequent to make diagnosis with X-ray or CT. Abdominal CT is more sensible than X-ray and shows a thickened bowel wall containing gas within submucosa or subserosa. 
Furthermore, CT scan shows complications such as perforation or pneumoperitoneum or signs of the underlying disease $[1,22]$. In our patient the CT report did not mention PCI, but a subsequent review of the images allowed to highlight the presence of gas in the same sites reported by the colonoscopy.

\section{Treatment}

Treatment of PCI is related on the underlying cause. There is not a specific treatment in asymptomatic patients. Conservative approaches (intestinal rest, antibiotic therapy and oxygen) are suitable in patients without complications requiring surgery [23]. A spontaneous remission is also possible. The medical history of the patient and his current drugs should be evaluated carefully to guide further decisions. Khalil et al. proposed a treatment algorithm to support the decision-making process; it is based on evaluation of clinical condition, laboratory and CT findings and medical history. It may help to reduce the rate of patients with benign forms of PCI unnecessarily subjected to exploratory surgery and reduce the delay in surgical therapy for those patients who would profit from early surgical intervention [20]. Our patient was completely asymptomatic, so we decided for rifaximin therapy and follow-up with endoscopic re-evaluation.

\section{Conclusion}

Pneumatosis cystoides intestinalis may be asymptomatic or sometimes diagnosed incidentally during colonoscopy. The treatment approach depends on underlying cause and it can be conservative or surgical in restricted cases.

\section{Conflict of interests}

The author declares that he has no conflict of interests.

\section{Funding}

This case report was not supported by relevant funds.

\section{Declaration of patient consent}

Informed consent of patients was obtained.

\section{References}

1. Wu LL, Yang YS, Dou Y, Liu QS (2013) A systematic analysis of pneumatosis cystoids intestinalis. World J Gastroenterol 19: 4973-4978. [Crossref]

2. Wang YJ, Wang YM, Zheng YM, Jiang HQ, Zhang J (2018) Pneumatosis cystoides intestinalis: six case reports and a review of the literature. BMC Gastroenterology 18 100. [Crossref]

3. Morris MS, Gee AC, Cho SD, Limbaugh K, Underwood S, et al. (2008) Management and outcome of pneumatosis intestinalis. Am J Surg 195: 679-682. [Crossref]

4. Kang G. Benign Pneumatosis Intestinalis Dilemma For Primary Care Clinicians. Can Fam Physician 63: 766-768. [Crossref]
5. Ling F, Guo D, Zhu L (2019) Pneumatosis cystoides intestinalis: a case report and literature review. BMC Gastroenterol 19: 176. [Crossref]

6. Ogul H, Pirimoglu B, Kisaoglu A, Karaca L, Havan N (2015) Pneumatosis Cystoides Intestinalis: An Unusual Cause of Intestinal Ischemia and Pneumoperitoneum. Int Surg 100: 221-224. [Crossref]

7. Wong CWY, Chung PHY, Wong KKY, Tam PK (2015) Pneumatosis intestinalis presenting as pneumoperitoneum in a teenage girl with pyloric stenosis. et al. $B M J$ Case Rep 2015: bcr2014208496. [Crossref]

8. Iida A, Naito H, Tsukahara K, Yumoto T, Nosaka N, et al. (2017) Pneumatosis cystoides intestinalis presenting as pneumoperitoneum in a patient with chronic obstructive pulmonary disease: a case report. J Med Case Rep 11: 55. [Crossref]

9. Tsujimoto T, Shioyama E, Moriya K, Kawaratani H, Shirai Y, et al. (2008) Pneumatosis cystoides intestinalis following alpha-glucosidase inhibitor treatment: A case report and review of the literature. World J Gastroenterol 14: 6087-6092. [Crossref]

10. Furio L, Vergura M, Russo A, Bisceglia N, Talarico S, et al. (2006) Pneumatosis coli induced by acarbose administration for diabetes mellitus. Case report and literature review. Minerva Gastroenterol Dietol 52: 339-346. [Crossref]

11. Morris-Stiff GJ, Williams RJ (1999) Pneumatosis cistoide intestinalis in a patient with dermatomyositis. J R Soc Med 92: 366-367. [Crossref]

12. Suzuki E, Kanno T, Hazama M, Kobayashi H, Watanabe H, et al. (2017) Four Cases of Pneumatosis Cystoides Intestinalis Complicated by Connective Tissue Diseases. Intern Med 56: 1101-1106. [Crossref]

13. de Beeck BO, Peters K, Spinhoven MJ, Snoeckx A, Salgado R (2009) Asymptomatic pneumatosis intestinalis in AIDS. JBR-BTR 92: 253-255. [Crossref]

14. Arikanoglu Z, Aygen E, Camci C, Akbulut S, Basbug M, et al. (2012) Pneumatosis cystoides intestinalis: a single center experience. World J Gastroenterol 18: 453-457. [Crossref]

15. Gillon J, Tadesse K, Logan RF, Holt S, Sircus W (1979) Breath hydrogen in pneumatosis cystoides intestinalis. Gut 20: 1008-1011. [Crossref]

16. Yale CE, Balish E (1992) The natural course of Clostridium perfringens-induced pneumatosis cystoides intestinalis. J Med 23: 279-288. [Crossref]

17. Doumit M, Saloojee N, Seppala R (2008) Pneumatosis intestinalis in a patient with chronic bronchiectasis. Can J Gastroenterol 22: 847-850. [Crossref]

18. Choi JY, Cho SB, Kim HH, Lee IH, Lee HY, et al. (2014) Pneumatosis Intestinalis Complicated by Pneumoperitoneum in a Patient with Asthma. Tuberc Respir Dis 77: 219-222. [Crossref]

19. Iida A, Naito H, Tsukahara K, Yumoto T, Nosaka N, et al. (2017) Pneumatosis cystoides intestinalis presenting as pneumoperitoneum in a patient with chronic obstructive pulmonary disease: a case report. J Med Case Rep 11: 55. [Crossref]

20. Khalil PN, Huber-Wagner S, Ladurner R, Kleespies A, Siebeck M, et al. (2009) Natural history, clinical pattern, and surgical considerations of pneumatosis intestinalis. Eur $J$ Med Res 14: 231-239. [Crossref]

21. Azzaroli F, Turco L, Ceroni L, Galloni SS, Buonfiglioli F, et al. (2011) Pneumatosis cystoides intestinalis. World J Gastroenterol 17: 4932-4936. [Crossref]

22. Aziret M, Erdem H, Ülgen Y, Kahramanca S, Cetinkünar S, et al. (2014) The appearance of free-air in the abdomen with related pneumatosiscystoides intestinalis: three case reports and review of the literature. Int J Surg Case Rep 5: 909-913. [Crossref]

23. Ellis BW (1980) Symptomatic treatment of primary pneumatosis coli with metronidazole. Br Med J 280: 763-764. [Crossref]

Copyright: (C2021 Loiodice A. This is an open-access article distributed under the terms of the Creative Commons Attribution License, which permits unrestricted use, distribution, and reproduction in any medium, provided the original author and source are credited. 